\title{
CYCLIC FATIGUE RESISTANCE OF NEWLY INTRODUCED SURFACE AND THERMAL TREATED NICKEL-TITANIUM ROTARY FILES
}

\author{
Hajer M. Abd ElHamid *
}

\begin{abstract}
Objectives The main objective of the present study invitro was to evaluate the cyclic fatigue resistance and metallurgic properties of newly thermal treated (CM wire) rotary $\mathrm{Ni}$-Ti files with different surface treatments.

Materials and Methods: A total of one hundred and twenty rotary files were used from three different rotary systems with the same thermomechanical treatment - controlled memory wire (CM Wire) and different surface treatment technique using rotation motion. Groups were set as Group 1: M3 Pro Gold (United Dental, Shanghai, China) (CM Wire) size (25/0.04), Group 2: AF F One Blue (Fanta Dental Material Co., Shanghai, China) [controlled memory wire (CM Wire)] size (25/0.04) and Group 3: Hyflex EDM (25/ 0.04). These files were tested for cyclic fatigue resistance using a custom-made static cyclic fatigue testing apparatus with various angles and radius (angle 60 radius $2.5 \mathrm{~mm}$ and $5 \mathrm{~mm}$ radius and angle 90 radius $2.5 \mathrm{~mm}$ and $5 \mathrm{~mm}$ ). Each rotary file was coated with EDTA after its attachment in handpiece supported in stainless steel cylinder apparatus. M3 Pro Gold rotary files, AF F one blue and Hyflex EDM rotary files were rotated at $500 \mathrm{rpm} 2.5 \mathrm{~N} / \mathrm{cm}$ torque according to manufacture instructions. Digital watch was used to record the time taken until file fracture in seconds and the $(\mathrm{NCF})$ number of cycles till fracture were calculated. Scanning electron microscope SEM image of the fractured surface were taken. Statistical analysis was performed using one-way analysis of variance and Tukey's test at the 95\% confidence level $(P=0.05)$.
\end{abstract}

Results: After comparing the cyclic fatigue resistance of AF F One Blue and M3 Pro Gold by recording time till the file fracture was ranged between 670 s to 1180 s in all groups at angle 60 degree with different radius and $10 \mathrm{~s}$ to $815 \mathrm{~s}$ in all groups at angle 90 degree with different radius. There were no significant differences between the M3 Pro Gold and AF F One Blue rotary files at angle 60 degree and 90 degree in both radius $2.5 \mathrm{~mm}$ and $5 \mathrm{~mm}(P>0.05)$, while there were significant differences between the Hyflex EDM and M3 Pro Gold and AF F One Blue rotary files at angle 60 degree, radius $2.5 \mathrm{~mm}(P>0.05)$. Hyflex EDM have the highly significant differences M3 Pro Gold and AF F One Blue rotary files at angle 90 degree, radius $2.5 \mathrm{~mm}(P<0.001)$.

Conclusions: All new thermomechanical treatment technique - controlled memory CM-Wire rotary systems represented great performance and remarkable enhancement in cyclic fatigue resistance but the Hyflex EDM rotary files had the highest cyclic fatigue resistance among the M3 Pro Gold and AF F one Blue rotary files. Also surface treatment of the rotary files enhancing the cyclic fatigue resistance by decreases surface micro cracks and the tendency to fracture.

Keywords: Metallurgic property, Controlled memory wire, Hyflex EDM, M3 Pro Gold, AF F One Blue, thermomechanical treatment

\footnotetext{
* Lecturer of Endodontic, Endodontic Department - MTI University - Cairo -Egypt
} 


\section{INTRODUCTION}

The Nickel-titanium (NiTi) rotary files are widely used now a days for shaping of root canal with different canal curvature. The unique properties of this alloy improves flexibility of NiTi rotary files reduces procedure errors during shaping of the root canals, especially during instrumentation of severely curved canals compared with conventional stainless steel hand files. ${ }^{[1]}$ Files separation of NiTi rotary instruments are still major issue during clinical application. ${ }^{[2,3]}$ Also another mechanical deficiency as cyclic fatigue are major complications, cyclic fatigue fractures occurs due to continuous tension and compression repeated cycles at the point of maximum flexure when the file rotates in a severely

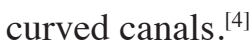

There are many factors contributed to broken files include instrument size, file cross-sectional, $\operatorname{design}^{[5,6]}$, metal surface treatments and the metallurgical characteristics of the Ni-Ti alloy, among others ${ }^{[7,8]}$. Therefore, attempts were made by several manufacturers for developing of special forms of thermomechanical processing, producing a superelastic NiTi alloy that contains a stable martensitic phase under clinical conditions ${ }^{[9]}$.

Many improvements in new manufacturing techniques as thermal and surface treatment have been developed to improve the mechanical properties, increasing the cyclic fatigue resistance of Ni-Ti rotary instruments. ${ }^{[10]}$ Thermomechanical processes which were applied to conventional NiTi wire improves and change the microstructure of NiTi alloy and therefore extends the files resistance to fracture and the life span. A special newly introduced NiTi alloy termed as M-wire introduced by (Dentsply, Tulsa, Oklahoma, USA) was developed by new advanced manufacturing technique. Its enhancement in flexibility and cyclic fatigue resistance is due to the unique nanocrystalline martensitic microstructure of the treated alloy. ${ }^{[1]}$ M-wire is currently used for the manufacturing of different rotary systems. Another thermal treatment procedure was developed termed R-Phase technology that optimizes the microstructure and mechanical properties also improves the fatigue resistance of the NiTi alloys. ${ }^{[12]}$

Recently, NiTi rotary instruments made from a NiTi controlled memory wire (CM wire, DS Dental, Johnson City, TN, USA) have been introduced. The manufacturer claims that these instruments have superior flexibility and fatigue resistance $300 \%$ than conventional NiTi rotary instruments made from superelastic wire ${ }^{[13]}$

The M3 Pro Gold Rotary file (United Dental, Shanghai, China) is a newly introduced NiTi instrument that is designed to be used in continuous rotation motion with an inactive tip and a convex triangular cross-section size 25/ 0.04 taper. The manufacturer claims that this instrument allows quick and safe preparation especially in curved root canals due to high flexibility. M3 Pro Gold files are manufactured with a CM wire associated with an advanced triple surface coating, which allows greater flexibility and cyclic fatigue resistance to the file ${ }^{[14]}$.

The AF F One Blue Rotary file (Fanta Dental Material Co., Shanghai, China) is also newly introduced NiTi instrument in the market that is designed to be used in continuous rotation motion with an inactive tip and a flat surface design 25/ 0.04 taper. The manufacturer claims that this instrument allows quick and safe preparation especially incurved root canals due to high flexibility, manufactured with a CM wire associated with a titanium oxide surface treatment, which allows better flexibility, hardness and resistance to fracture ${ }^{[15]}$.

Hyflex EDM Rotary file (Coltene/Whaledent, Cuyahoga Falls, Ohio, USA), a CM wire with advance surface treatment electrical discharged machining technique (EDM) giving the crater like appearance of the surface represented by pitting and dimpling with variable taper and different cross section giving the file greater flexibility, hardness and resistance to cyclic fatigue. ${ }^{[16]}$ 


\section{MATERIALS AND METHODS}

In this study one hundred and twenty rotary files were used from three different rotary systems with the same thermomechanical treatment controlled memory wire (CM Wire) and different surface treatment technique using rotation motion.

Group 1: M3 Pro Gold (United Dental, Shanghai, China) (CM Wire), Group 2: AF F One Blue (Fanta Dental Material Co., Shanghai, China) (CM-Wire) and Group 3: Hyflex EDM (Coltene/Whaledent, Cuyahoga Falls, Ohio, USA). Each group contained 40 files with (IS0 tip size \# 25 and a 0.04 taper). Before applying the cyclic fatigue test, each file was tested for any possible manufacturing defects and deformation with a scanning electron microscope SEM (Quanta FEG 250, Egypt) under magnification of $200 X$ to $3000 X$.

The cyclic fatigue test was preformed using a custom-made apparatus that was specially designed for this experiment by using a modification of the apparatus described by Larsen et al. ${ }^{[8]}$ and Capar et al. ${ }^{[9]}$

A Cyclic fatigue testing block was fabricated as a stainless-steel metal block with dimensions $9.5 \mathrm{~cm}$ length $\mathrm{x} 4 \mathrm{~cm}$ height and $0.5 \mathrm{~mm}$ in thickness. Four simulated canals were created in this stainless-steel block ( 2 with angle $90^{\circ}$ radius $2.5 \mathrm{~mm}$ and $5 \mathrm{~mm}$ ) and (2 with angle $60^{\circ}$ radius $2.5 \mathrm{~mm}$ and $5 \mathrm{~mm}$ ) all files 0.04 taper and tip diameter with $0.2 \mathrm{~mm}$ offset for canal width. The depth of the simulated canals was $2 \mathrm{~mm}$ to accommodate the size and taper of the files thus providing the instrument with a suitable trajectory. A flexiglass cover that prevent fractured part of the file from slipping out was attached to the side of the block. Figure (1a) Four holes were made at the corners of the cyclic fatigue testing block to allow for fixation of the block to the cyclic fatigue testing apparatus. For each of the tested rotary files solid works software (Dassault Systèmes, S. A. Vélizy, France) was used to determine canal geometry that follow the tested file. The angle of curvature was calculated by Pruett's method 4 which is described as the curvature radius for measuring root canal curvatures, this method which defines the canal shape using two parameters: the angle of curvature and the radius of curvature Figure (1a)

Cyclic fatigue testing apparatus is a custommade stainless-steel apparatus which was designed as described by Gianluca Plotino ${ }^{[17]}$. The apparatus was made from stainless steel and was composed of a $2 \mathrm{~cm}$ thick stainless-steel sheet, which is considered the main part with $60 \mathrm{~cm} \times 60 \mathrm{~cm}$ dimensions. In the upper right two parallel slots $40 \mathrm{~cm}$ in length were made which are used in fixing the upper sliding stainless sheet of dimensions $10 \mathrm{~cm}$ x $10 \mathrm{~cm}$ which was considered the movable tray that made positioning the hand-piece easy and reproducible. Fixing the two sheets together was done by the presence of 2 screws on the upper slot while the stainless-steel block was fixed by other 2 screws found on its top surface also found on the movable stainless sheet with diameter $2 \mathrm{~mm}$. Also, the handpiece rested to the main sheet by a non-movable tray which was fixed to, the main sheet by 4 screws and it was stabilized to the non-movable sheet by two cable ties passing through 4 slots. Figure (1b)

Cyclic fatigue testing after the hand piece was mounted on the apparatus, then each instrument according to each group and subgroup was precisely positioned to the block. Instruments were rotated until fracture occurs and time taken for fracture was recorded. The instruments were rotated at torque and speed according to manufacture instruction of files using a 16:1 reduction hand piece (ENDOMATE TC2 Reduction Heads from NSK, Japan) powered by a torque-controlled electric motor (ENDO-MATE TC2 Motor from NSK, Japan). A synthetic oil (Pana spray plus from NSK, Japan) filled all the stainless-steel canal space was used to reduce the friction of the file with block before testing every file. A flexiglass top cover was used to allow visualization of the file while rotating in the canal and the fracture of the instrument it also helped in maintaining the oil in the canal for a longer period and preventing the file from deviating out of the canal space. 


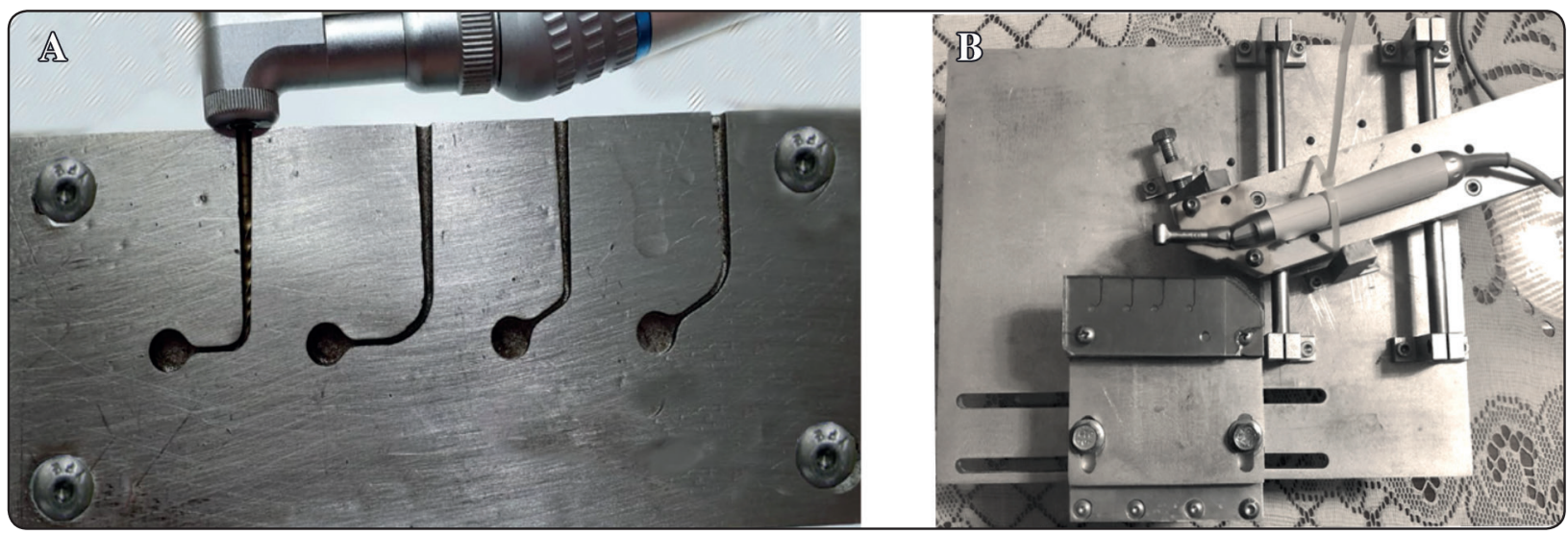

Fig. (1): Cyclic fatigue testing block (a); Cyclic fatigue testing apparatus(b)

\section{Method of evaluation:}

A- Number of Cycles to Failure (NCF): Static cyclic fatigue testing was performed for each file at $500 \mathrm{rpm}$ and torque $2.5 \mathrm{~N} / \mathrm{cm}$ for $3 \mathrm{M}$ pro Gold, AF Fone Blue and Hyflex EDM with continuous rotation. Working length was standardized to $16 \mathrm{~mm}$ for each file. During the testing, engine oil was used to reduce the friction between files and metal block. All files were rotated until fracture occurred and the time to fracture was recorded in seconds. The length of the fractured file tip was also measured with a digital micro caliper (Aydal, Istanbul, Turkey) and recorded. Instrument fracture was visually and audibly detected and the time until fracture was recorded in seconds by using a digital stopwatch manually operated, started at the moment the motor was turned on, and stopped at fracture detection. All fatigue tests were performed by the same operator the number of cycles to fracture (NCF) was then calculated using the simple formula: Number of rotations $=($ recommended speed per minute $x$ time to fracture in minutes) ${ }^{[18]}$

B-Mode of failure: The fractured segments were collected and ultrasonically cleaned in an ultrasonic bath using absolute alcohol for 90 seconds. To remove the debris and the oil remnants from the surface of the file before the examination to determine the fracture mode, random samples were chosen to be tested under scanning electron microscope (SEM) (Quanta FEG 250, Egypt). Samples were mounted vertically then horizontally to obtain top view and lateral view respectively using various magnifications ranging from $200 x$ to 3000x:

1- Top views with high magnification were taken to evaluate the details and patterns of cyclic fatigue fracture.

2- Lateral views were taken to evaluate signs of plastic deformation (if any), disruptions of cutting edge and manufacturing grooves and quality of surface treatment of the files of the three groups. ${ }^{[19]}$

The instruments were investigated under SEM for topographic features of the separated part of the file that all are explained in Table 1.

\section{Statistical analysis:}

Statistical analysis was performed by Microsoft office 365 (Excel) and Statistical Package for Social Science (SPSS) version 20. Means and standard deviations of (NCF) number of cycles till fracture were calculated for each group. The data were analyzed by variables ANOVA two-way analysis of variance and Tukey's test was performed at the $95 \%$ confidence level $(P=0.05)$. All statistical analyses were performed using SPSS software (SPSS Inc, Chicago, Illinois, USA). 
TABLE (1) Patterns and signs of cyclic fatigue fracture.

\begin{tabular}{|l|l|}
\hline Defect & Definition \\
\hline Metallic strips & Visible flashes of metal protruding irregularly from the surface \\
\hline Metallic folds & Rolled over metallic dim appearing along the cutting edge \\
\hline Disruption of the cutting edges & The loss of the regular continuous shape of the blades \\
\hline Micro fractures & $\begin{array}{l}\text { A surface defect that appears as surface fissuring and discontinuity, it appears mainly as } \\
\text { accentuation of machine grooving. }\end{array}$ \\
\hline Cracks & Break down without complete separation of parts \\
\hline Fractures & Complete separation of parts \\
\hline Scrapings & Removed areas from surface which may be due to excessive frictional force \\
\hline Pitting & Small, excavated and punched out areas on the surface \\
\hline Craters & Large excavated areas on the surface \\
\hline Corrosion & $\begin{array}{l}\text { Disintegration of the NiTi alloy due to chemical reaction appears darker in the color than the } \\
\text { rest of the surface }\end{array}$ \\
\hline Fretting & Observable corrosion with friable surface texture \\
\hline Debris & Small particles made of materials removed from the canal \\
\hline
\end{tabular}

\section{RESULTS}

\section{Effect of file type, angle of curvature and radius on Number of cycles to failure (NCF):}

The mean values and standard deviations of Number of Cycles to Failure (NCF) of each group were calculated and represented in Table $(2,3)$. At angle 60 degree; there were no significant differences between the three groups in $5 \mathrm{~mm}$ radius $(\mathrm{P}<0.05)$ while in $2.5 \mathrm{~mm}$ radius there were no significant differences between the M3 Pro Gold group and the AF F One Blue group $(\mathrm{P}<0.05)$ and there were significant differences between the Hyflex EDM and the other two groups $(\mathrm{P}>0.05)$. At angle 90 degree; there were no significant differences between M3 Pro Gold and AF F One Blue rotary file in $5 \mathrm{~mm}$ radius $(\mathrm{P}<0.05)$ and significant differences between the Hyflex EDM and the other two groups $(\mathrm{P}>0.05)$ whilst in $2.5 \mathrm{~mm}$ radius there were no significant differences between M3 Pro Gold and AF F One Blue rotary file ( $\mathrm{P}<$ $0.05)$ and highly significant differences between the Hyflex EDM and the other two groups (P >0.001) Figure 2.

Table (2) Mean values ( \pm standard deviation) for number of cycles to fracture of each group

\begin{tabular}{|c|c|c|c|c|}
\hline \multirow{2}{*}{ Radius } & Radius & M3 Pro Gold & AF F one Blue & Hyflex EDM \\
\hline \multirow{2}{*}{60 Degree Angle } & $2.5 \mathrm{~mm}$ & $6981.75 \pm 421.6$ & $6774.61 \pm 985.82$ & $7982.41 \pm 396.63$ \\
\cline { 2 - 5 } & $5 \mathrm{~mm}$ & $7636.93 \pm 716.72$ & $7526.89 \pm 661.99$ & $8359.21 \pm 880.72$ \\
\hline \multirow{2}{*}{90 Degree Angle } & $2.5 \mathrm{~mm}$ & $134.82 \pm 40.403$ & $207.99 \pm 154.87$ & $4558.8 \pm 1499.9$ \\
\cline { 2 - 5 } & $5 \mathrm{~mm}$ & $4095.9 \pm 1175$ & $3504.9 \pm 1108.1$ & $5294.2 \pm 929.72$ \\
\hline
\end{tabular}


TABLE (3) The significant differences between all groups at angles 60 and 90 and radii $2.5 \mathrm{~mm}$ and $5 \mathrm{~mm}$

\begin{tabular}{|l|c|c|c|c|}
\hline & \multicolumn{2}{|c|}{ Angle 60 degree } & \multicolumn{2}{c|}{ Angle 90 degree } \\
\cline { 2 - 5 } & $2.5 \mathrm{~mm}$ Radius & $5 \mathrm{~mm}$ Radius & $2.5 \mathrm{~mm}$ Radius & $5 \mathrm{~mm}$ Radius \\
\hline M3 Pro Gold vs AF F one Blue & $\mathrm{ns} \mathrm{P}>0.05$ & $\mathrm{~ns} \mathrm{P}>0.05$ & $\mathrm{~ns} \mathrm{P}>0.05$ & $\mathrm{~ns} \mathrm{P}>0.05$ \\
\hline M3 Pro Gold vs Hyflex & $* \mathrm{P}<0.05$ & $\mathrm{~ns} \mathrm{P}>0.05$ & $* * \mathrm{P}<0.001$ & $* \mathrm{P}<0.05$ \\
\hline AF F one Blue vs Hyflex & $* \mathrm{P}<0.05$ & $\mathrm{~ns} \mathrm{P}>0.05$ & $* * \mathrm{P}<0.001$ & $* \mathrm{P}<0.05$ \\
\hline
\end{tabular}

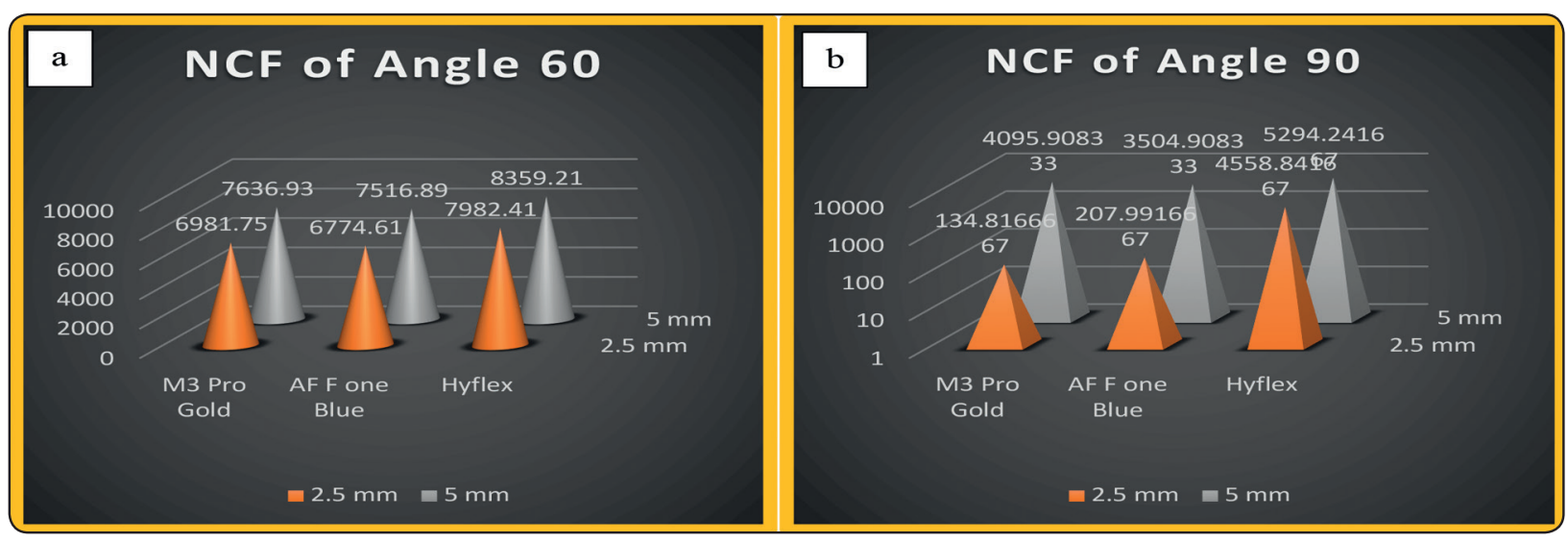

Fig. (2) Bar chart showing the effect of different radii of curvature on NCF in 60 degree angle (a) and 90 degree angle (b) using the three types of rotary files

\section{II-Results of Scanning Electron Microscope:}

Scanning Electron Microscope images cross section view of a samples of the fracture surface of M3 Pro Gold, AF F one Blue and Hyflex EDM at $800 \mathrm{X}$ and $1600 \mathrm{X}$ magnification showed similar and typical features of cyclic fatigue pattern which have high resemblance to ductile fracture (ability of the material to undergo plastic deformation before fracture); where micro voids produced within the metal, nucleation growth and micro voids coalescence which ultimately weaken the metal result in fracture, concentric abrasion marks and fibrous dimple marks at the center of rotation was observed. Plastic deformation seen because of slip; the process by which a dislocation moves in response to shear stresses, also contributes to ductile fracture. are shown in Figures (3)

Scanning electron microscopy longitudinal view of sample of each group at $200 \mathrm{X}$ and $3000 \mathrm{X}$ magnification showed the different surfaces treatment of the rotary files; the titanium oxide coating of AF F One Blue which shows continuous homogenous coating with disruption of the cutting edges surface and M3 Pro Gold coated with advanced surface treatment technique showed disruption of the cutting edges surface. Hyflex EDM showed a crater like surface with pitting and dimpling surface. Figure 4 


\section{Cross section view}
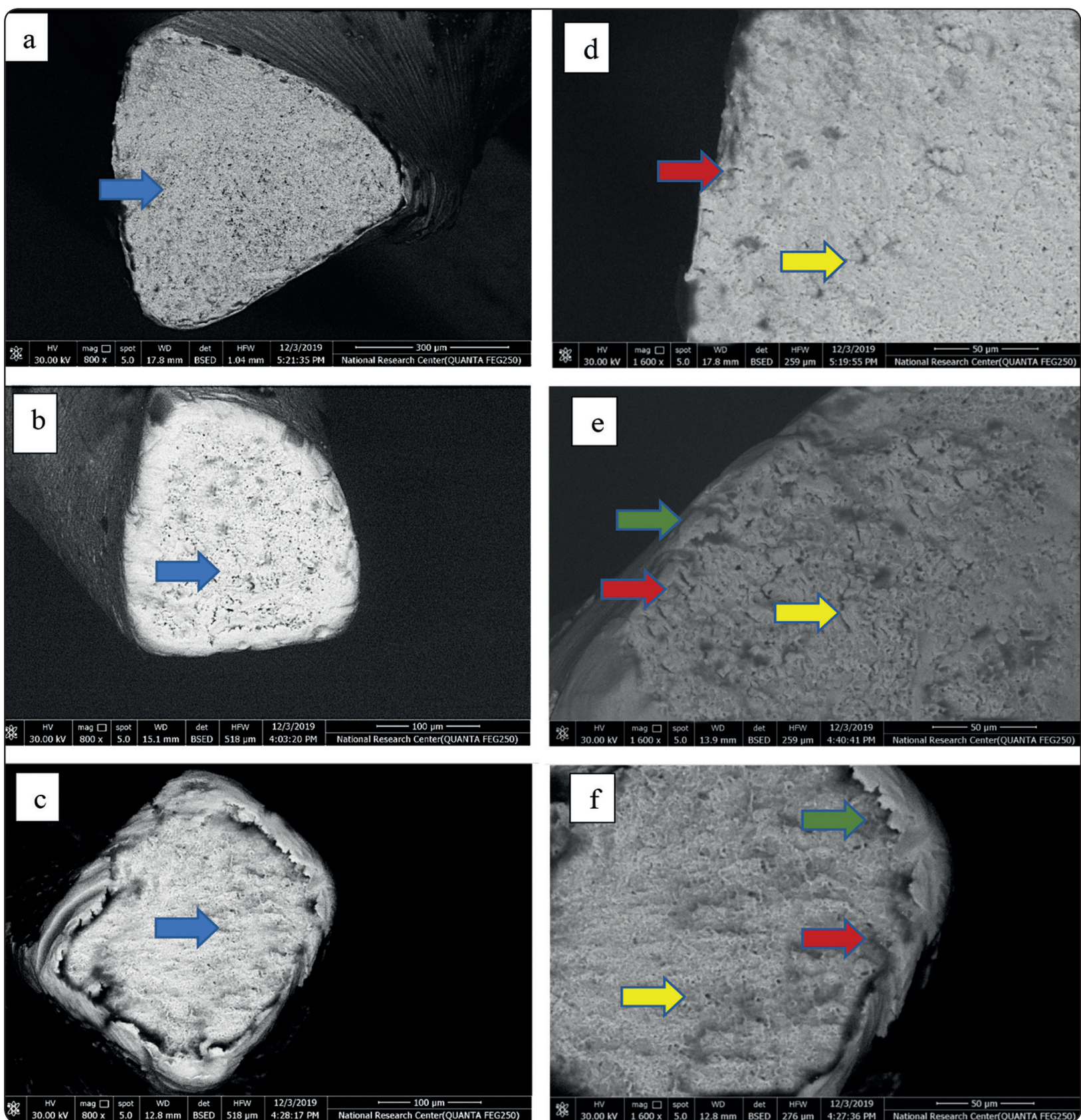

Fig. (3) SEM image for Top view of fractured M3 Pro Gold (a,d), AF F one Blue (b,e) and Hyflex EDM (c,f) rotary files at magnification of $800 \mathrm{X}$ and $1600 \mathrm{X}$ showing the different cross sections of the files, the fibrous appearance indicating ductile fracture (blue arrow), metallic folds as rolling of the edges (green arrow) and pitting yellow arrow, the surface microcracking (Red arrow) 


\section{Longitudinal view}

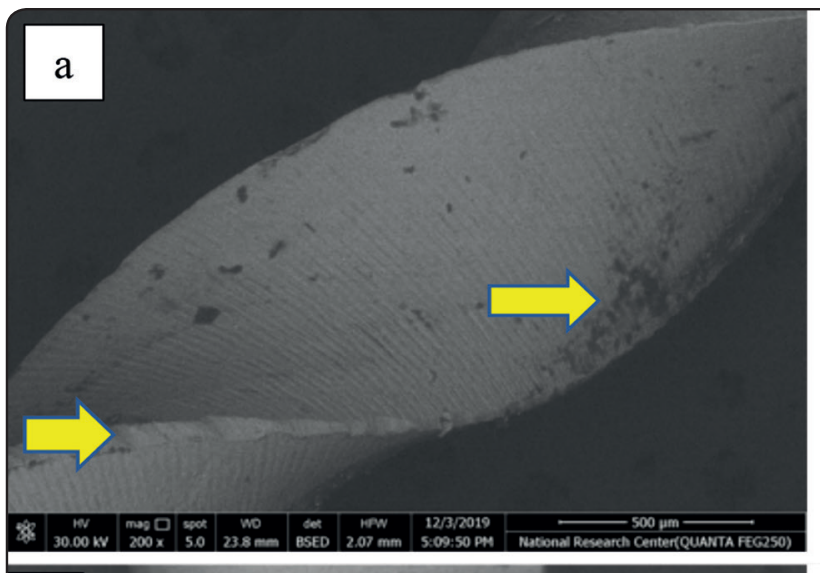

\section{d}
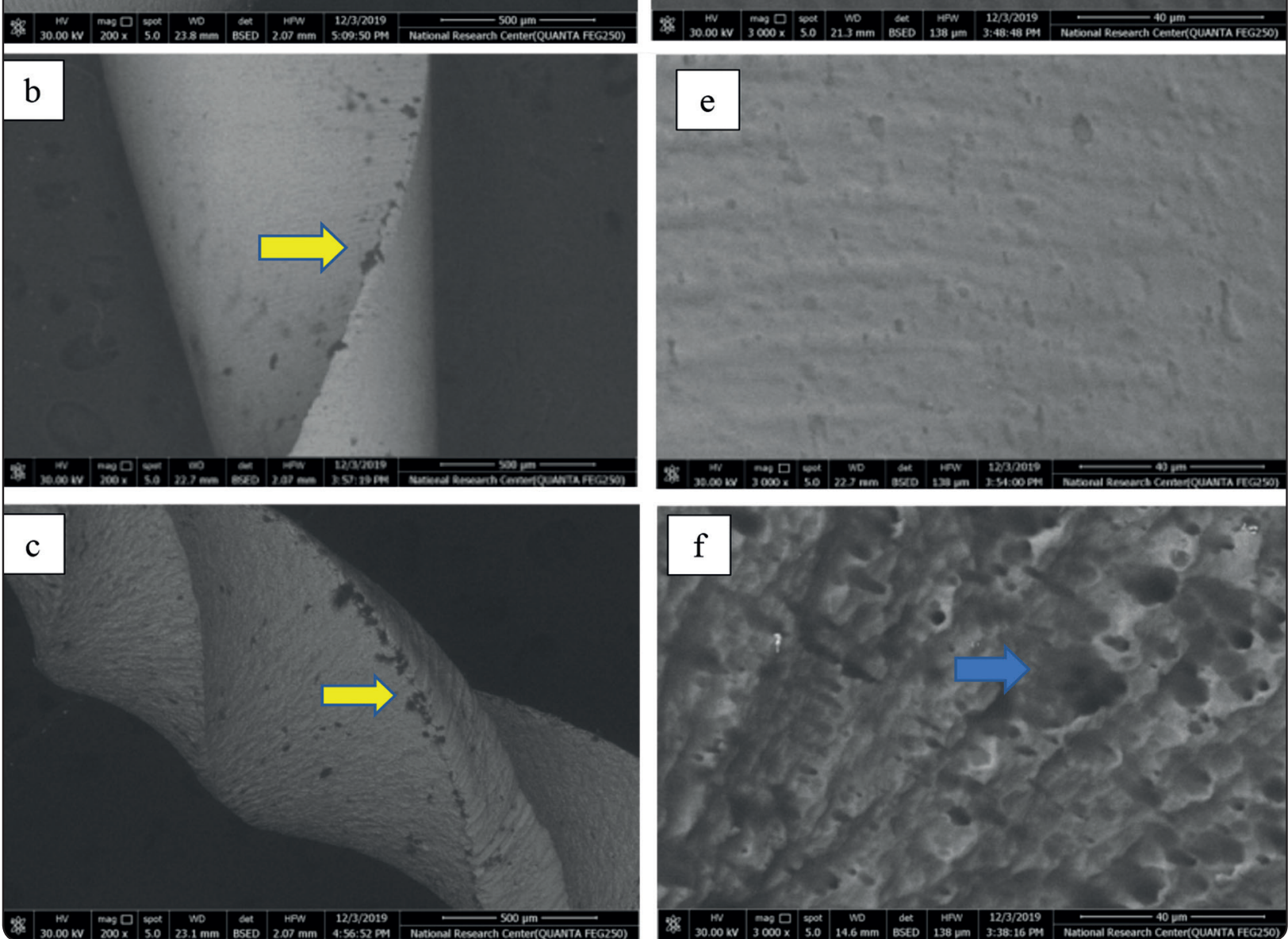

Fig. (4) SEM image for longitudinal view for the surface treatment of fractured M3 Pro Gold (a,d), AF F one Blue (b,e) and Hyflex $\operatorname{EDM}(\mathrm{c}, \mathrm{f})$ rotary files at magnification of $200 \mathrm{X}$ and $3000 \mathrm{X}$ showing multiple pitting and dimpling (blue arrow), disruption of the cutting edges and surface (yellow arrow) 


\section{DISCUSSION}

New generation of rotary files are fabricated from thermo-mechanically treated alloys have enhanced the resistance to cyclic fatigue and increase flexibility in addition to surface treatment that enhance the hardness of the files and decreases tendency file fracture. Factors influencing the fatigue resistance include file design, cross-sectional geometry and diameters of core, tip size, and taper of the tested file. ${ }^{[20,21]}$ Furthermore, radii and degree of curvature, rotation speed, torque, and movement kinematics (continuous, reciprocal, or adaptive) also perform an important role in the cyclic fatigue resistance of files. ${ }^{[22]}$

Gao Yet al. ${ }^{[23]}$ mentioned in his study that the speed and type of motion (reciprocal or rotational) of files may also affect the cyclic fatigue resistance. For these reasons, standardization of these variables is a must. Although, several studies compared the cyclic fatigue resistance of different NiTi rotary files, with different cross section, degree of taper, or different sizes. ${ }^{[4,6,8,21]}$ By this way, only the influence of the difference of manufacturer method and the surface treatment of the files on cyclic fatigue could be compared.

In this present study, standardized of artificial canals $\left(60^{\circ}\right.$ and $90^{\circ}$ angle of curvature and a curvature radius of $2.5 \mathrm{~mm}$ and $5 \mathrm{~mm}$ ) and same torque, rotation speed $(500 \mathrm{rpm})$, rotation type (continuous) were set to minimize the influence of variables and also all groups were CM-wire different manufacturing methods influenced the fatigue resistance of the endodontic files produced by different companies and different surface treatment. Shen et al. ${ }^{[13,24]}$ observed increased fatigue resistance in files manufactured via proprietary $\mathrm{CM}$ wire processing. The superiority of $\mathrm{CM}$ files in terms of cyclic fatigue resistance was also proven in previous studies. ${ }^{[4,25,26]}$ The reason for this may be that for a given strain, a more flexible file would experience less stress, allowing for a longer fatigue lifetime ${ }^{[27]}$. Cyclic fatigue behavior of the files using time to fracture data was compared. Similar to the present assessment method, previous researchers used number of cycles to fracture for the failure of files $[8,9,7,10,20]$

The AF F One Blue Rotary files, M3 Pro Gold and Hyflex EDM rotary files were compared because they have the same thermomechanical treatment in their manufacturing technique (CM wire) but differ in surface treatment and design and geometrical features. Sizes 25 with 0.04 taper of instruments were tested because these sizes are commonly used during instrumentation. ${ }^{[21]}$

According to results, when same size of the instruments was compared, the Hyflex EDM files exhibited higher cyclic fatigue resistance and angular rotation to fracture than M3 Pro Gold and AF F One Blue Rotary files especially at angle 90 degree radius $2.5 \mathrm{~mm}$, while no significant difference was observed between M3 Pro Gold and AF F One Blue Rotary files at angle 60 and 90 degree with both radius. These results are probably due to the different NiTi alloys treatment temperature and the differences in surface coating and treatment ${ }^{[28,29]}$.

Pedullà E et al. ${ }^{[30]}$ conducted DSC analysis to M3 Pro Gold files, as CM wire, which showed a mixture of martensite and austenite at room temperature. In particular, M3 Pro Gold files were measured to be $36.39^{\circ} \mathrm{C}$, at their heating curves. This means that at human body temperature (around $37^{\circ} \mathrm{C}$ ) ${ }^{[31]}$, the M3 Pro Gold files are in a mixed austenite and martensite phase. Since martensite is less stiff than austenite and Martensite is more likely to deform than austenite because it has a twinning process, which refers to an internal movement of lattices without breaking atomic bonds by absorbing stress. ${ }^{[32]}$

The AF F one Blue files were introduced to produce NiTi instruments by an innovative methodology (a complex heating and cooling treatment) that uses a unique process that controls the material's memory similarly to the shape memory NiTi rotary files. 
HyFlex EDM rotary files, mainly composed of martensite and $\mathrm{R}$ phase, revealed special structural properties, such as increased phase transformation temperatures and higher hardness when compared with other manufactured $\mathrm{CM}$ wire instruments. The increase in the plasticity of thermally treated files is thought to be due to the increase of the proportions of the R-phase and martensite. The R-phase has the lowest shear modulus among the 3 phases ${ }^{[33]}$. The different phase composition and the improved hardness may shed light on the enhanced mechanical behavior of electro-discharge machined instruments. ${ }^{[34]}$ These findings with (Gündoğar $M$ and Özyürek T)

Anderson et al. ${ }^{[35]}$ concluded that electro-polishing surfacing is likely reduce surface irregularities that serve as points of stress concentration and crack initiation. Manufacturing process may serve as nucleating sites for the micro-voids and crack propagation at grain boundaries and surfaces leading to instrument fractures during clinical use Alapati et al. ${ }^{[36]}$ The high density of surface defects facilitates the crack nucleation stage and the fatigue failure is largely a crack propagation process $K \boldsymbol{K h n}$ et $\boldsymbol{a l}{ }^{[37]}$. Thus, it is possible that the multitude of machining marks on the surface of a ground instrument would lead to crack initiation at multiple locations in which the resolved shear stress is greater than that required for crystallographic slip to occur Kim et al. ${ }^{[38]}$

Under the conditions of this study, the surface treated instruments may improve cyclic fatigue resistance while maintaining the torsional resistances and mechanical properties, this within agreement Kim et al. ${ }^{[39]}$ and Plotino G et al ${ }^{[40]}$.

\section{CONCLUSIONS}

All new thermomechanical treatment technique - controlled memory CM-Wire rotary systems represented great performance and remarkable enhancement in cyclic fatigue resistance but the
Hyflex EDM rotary files had the highest cyclic fatigue resistance among the M3 Pro Gold and AF F one Blue rotary files. Also surface treatment of the rotary files enhancing the cyclic fatigue resistance by decreases surface micro cracks and the tendency to fracture.

\section{REFERENCES}

1. Peters OA. Current challenges and concepts in the preparation of root canal systems: A review. J Endod 2004; 30:559-67.

2. Sattapan B, Nervo GJ, Palamara JE, Messer HH. Defects in rotary nickel-titanium files after clinical use. J Endod 2000;26:161-65.

3. Parashos $\mathrm{P}$, Messer HH. Rotary NiTi instrument fracture and its consequences. J Endod. 2006 Nov;32(11):1031-43.

4. Capar ID, Ertas H, Dds HA. Comparison of cyclic fatigue resistance of novel nickel-titanium. J Endod 2014:1-5.

5. Zhang E-W, Cheung GS, Zheng Y-F. Influence of crosssectional design and dimension on mechanical behavior of nickel-titanium instruments under torsion and bending: A numerical analysis. J Endod 2010;36:1394-98.

6. Martin B, Zelada G, Varela P, Bahillo J, Magán F, Ahn S, et al. Factors influencing the fracture of nickel-titanium rotary instruments. Int Endod J 2003;36:262-66.

7. Gambarini G, Gergi R, Grande NM, Osta N, Plotino G, Testarelli L. Cyclic fatigue resistance of newly manufactured rotary nickel titanium instruments used in different rotational directions. Aust Endod J 2013; $39: 151-54$.

8. Larsen CM, Watanabe I, Glickman GN, He J. Cyclic fatigue analysis of a new generation of nickel titanium rotary instruments. J Endod 2009;35:401-03.

9. Capar ID, Ertas H, Arslan H. Comparison of cyclic fatigue resistance of novel nickel-titanium rotary instruments. Aust Endod J 2015;41:24-28.

10. Lopes HP, Gambarra-Soares T, Elias CN, Siqueira JF, Inojosa IFJ, Lopes WSP, et al. Comparison of the mechanical properties of rotary instruments made of conventional nickel-titanium wire, M-Wire, or nickel-titanium alloy in R-Phase. J Endod 2013;39:516-20

11. Ye J, Gao Y. Metallurgical characterization of M-Wire nickel- titanium shape memory alloy used for endodontic 
rotary instruments during low-cycle fatigue. J Endod 2012; 38:105-07.

12. Pérez-Higueras JJ, Arias A, de la Macorra JC. Cyclic fatigue resistance of $\mathrm{K} 3, \mathrm{~K} 3 \mathrm{XF}$, and twisted file nickel-titanium files under continuous rotation or reciprocating motion. J Endod 2013;39:1585-88.

13. Shen Y, Zhou H-m, Zheng Y-f, Campbell L, Peng B, Haapasalo M. Metallurgical characterization of controlled memory wire nickel-titanium rotary instruments. J Endod 2011;37:1566-71.

14. Pedullà E, Lo Savio F, La Rosa GRM et al. Cyclic fatigue resistance, torsional resistance, and metallurgical characteristics of M3 Rotary and M3 Pro Gold NiTi files. Restor Dent Endod. 2018; 23: 43(2)

15. Shangahai Fanta catalogue 2018-2019.pdf

16. Pirani C , Iacono F, Generali L et al. HyFlex EDM: superficial features, metallurgical analysis and fatigue resistance of innovative electro discharge machined NiTi rotary instruments. Int Endod J. 2016 May;49(5):483-93.

17. Plotino G, Grande NM, Cordaro M, Testarelli L, Gambarini G. A Review of Cyclic Fatigue Testing of Nickel-Titanium Rotary Instruments. J Endod. 2009;35(11):1469-1476.

18. Bhatt A, Rajkumar B. A comparative evaluation of cyclic fatigue resistance for different endodontic NiTi rotary files: An in-vitro study. J Oral Biol Craniofacial Res. 2019;9(2):119-121.

19. Kim H, Yum J, Hur B. Cyclic Fatigue and Fracture Characteristics of Ground and. J Endod. 2010;36(1):147- 152.

20. Bouska J, Justman B, Williamson A, DeLong C, Qian F. Resistance to cyclic fatigue failure of a new endodontic rotary file. J Endod 2012;38:667-69.

21. Al-Hadlaq SM. Evaluation of cyclic flexural fatigue resistance of 25/0.04 and 25/0.06 twisted file rotary nickel-titanium endodontic instruments. Aust Endod J 2013;39:62-5.

22. Wan J, Rasimick BJ, Musikant BL, Deutsch AS. A comparison of cyclic fatigue resistance in reciprocating and rotary nickel- titanium instruments. Aust Endod J 2011;37:122-27.

23. Gao Y, Shotton V, Wilkinson K, Phillips G, Johnson WB. Effects of raw material and rotational speed on the cyclic fatigue of ProFile Vortex rotary instruments. J Endod. $2010 \mathrm{Jul} ; 36(7): 1205-9$.

24. Shen Y, Qian W, Abtin H, Gao Y, Haapasalo M. Fatigue testing of controlled memory wire nickel-titanium rotary instruments. J Endod 2011;37:997-1001.
25. Gambarini G, Grande NM, Plotino G, Somma F, Garala M, De Luca M, et al. Fatigue resistance of engine-driven rotary nickel- titanium instruments produced by new manufacturing methods. J Endod 2008;34:1003-05.

26. Braga LCM, Silva ACF, Buono VTL, de Azevedo Bahia MG. Impact of heat treatments on the fatigue resistance of different rotary nickel-titanium instruments. J Endod 2014;40:1494-97. 23.

27. Pereira E, Peixoto I, Viana A, Oliveira I, Gonzalez B, Buono V. Physical and mechanical properties of a thermomechanically treated NiTi wire used in the manufacture of rotary endodontic instruments. Int Endod J 2012;45:469-74.

28. Gambarini G, Plotino G, Grande N, Al-Sudani D, De Luca M, Testarelli L. Mechanical properties of nickel-titanium rotary instruments produced with a new manufacturing technique. Int Endod J 2011;44:337-41.

29. Rodrigues RCV, Lopes HP, Elias CN, Amaral G, Vieira VTL, De Martin AS. Influence of different manufacturing methods on the cyclic fatigue of rotary nickel-titanium endodontic instruments. J Endod 2011;37:1553-57.

30. Pedullà E, Lo Savio F, La Rosa GRM, Miccoli G, Bruno E, Rapisarda S, Chang SW, Rapisarda E, La Rosa G, Gambarini G, Testarelli L. Cyclic fatigue resistance, torsional resistance, and metallurgical characteristics of M3 Rotary and M3 Pro Gold NiTi files. Restor Dent Endod. 2018; 23;43(2):e25.

31. De Vasconcelos RA, Murphy S, Carvalho CA, Govindjee RG, Govindjee S, Peters OA. Evidence for reduced fatigue resistance of contemporary rotary instruments exposed to body temperature. J Endod. 2016;42:782-787.

32. Kusy RP. A review of contemporary archwires: their properties and characteristics. Angle Orthod. 1997;67:197-207.

33. Iacono F, Pirani C, Generali L, Bolelli G, Sassatelli P, Lusvarghi L, Gandolfi MG, Giorgini L, Prati C Structural analysis of HyFlex EDM instruments. Int Endod J. 2017 Mar;50(3):303-313.

34. Gündoğar M, Özyürek T. Cyclic Fatigue Resistance of OneShape, HyFlex EDM, WaveOne Gold, and Reciproc Blue Nickel-titanium Instruments. J Endod. 2017 Jul; 43(7):1192-1196.

35. Anderson ME, Price JW, Parashos P. 2007. Fracture resistance of electropolished rotary nickel-titanium endodontic instruments. J Endod 33:1212-1216. 
36. Alapati SB, Brantley WA, Svec TA, Powers JM, Nusstein JM, Daehn GS. 2005. SEM observations of nickel-titanium rotary endodontic instruments that fractured during clinical use. J Endod 31:40-43.

37. Kuhn G, Tavernier B, Jordan L. 2001. Influence of structure on nickel-titanium endodontic instruments failure. J Endod 27:516-520.

38. Kim HC, Yum J, Hur B, Cheung GS. 2010. Cyclic fatigue and fracture characteristics of ground and twisted nickeltitanium rotary files. J Endod 36:147-152.

39. Kim BH1, Ha JH, Lee WC, Kwak SW, Kim HC. Effect from surface treatment of nickel-titanium rotary files on the fracture resistance. $2015 \mathrm{Jan}-\mathrm{Feb} ; 37(1): 82-7$.

40. Plotino G1, Grande NM2, Cotti E3, Testarelli L2, Gambarini G2. Blue treatment enhances cyclic fatigue resistance of vortex nickel-titanium rotary files. J Endod. 2014 Sep; 40(9):1451-3. 